\title{
The Biology of Sesamia inferens (Walker) (Lepidoptera: Noctuidae) on Maize in the North Western Plains of India
}

\author{
K. VISWAJYOTHI ${ }^{1} *$, N. AGGARWAL ${ }^{2}$ and J. JINDAL ${ }^{3}$ \\ ${ }^{1}$ Kerala Agricultural University, Thiruvananthapuram, 695522, Kerala, India \\ ${ }^{2}$ Department of Entomology, Punjab Agricultural University (PAU), Ludhiana, 141004, Punjab, India \\ ${ }^{3}$ Maize Section, Department of Plant Breeding and Genetics, PAU, Ludhiana, Punjab, India, 141001
}

(Received: 17 August 2018; accepted: 7 November 2018)

\begin{abstract}
The biology of Sesamia inferens (Walker) was studied at $25 \pm 1^{\circ} \mathrm{C}$ and $70 \pm 5$ per cent relative humidity on PMH 1 maize hybrid. The incubation period was $6.82 \pm 0.05$ days. There were six larval instars and the larval development was completed in $29.95 \pm 0.16$ days. The duration of instars I-VI was $4.17 \pm 0.09$, $3.60 \pm 0.08,4.47 \pm 0.02,4.40 \pm 0.03,6.18 \pm 0.06$ and $7.13 \pm 0.05$ days, respectively. The pre-pupal period was $2.83 \pm 0.02$ days. The male and female pupa had duration of $8.05 \pm 0.12$ days and $10.33 \pm 0.16$ days, respectively. The adult emergence was $93.02 \pm 0.01$ per cent, with a sex ratio of 1:1.05. The males had shorter longevity of $3.92 \pm 0.23$ days, while females had $5.05 \pm 0.28$ days. The pre-oviposition, oviposition and post-oviposition period was $1.11 \pm 0.10,2.96 \pm 0.19$ and $0.79 \pm 0.10$ days, respectively. The fecundity was $211.92 \pm 11.92$ eggs with $53.69 \pm 10.78$ eggs per cluster. The egg hatchability was $92.19 \pm 0.01$ per cent. The total life cycle was completed in $47.65 \pm 0.24$ days (Male) and $49.93 \pm 0.21$ days (female). The observations on the biology will help in developing efficient strategies to manage $S$. inferens on maize in the north western plains of India.
\end{abstract}

Keywords: Biology, instar, maize, pink stem borer.

Maize (Zea mays L.; Poaceae) is a versatile crop grown over a wide range of agro climatic zones. Advancement of agricultural technologies enabled the cultivation of maize throughout the year in different parts of India. This coupled with improper pesticide usage has led to the wide spread occurrence of various pests in the non conventional areas. Pink stem borer, Sesamia inferens (Walker) is a polyphagous pest attacking various graminaceous crops. The species was originally described in the genus Leucania by Walker in 1856, which got later transferred to the genus Sesamia (Hampson et al., 1912). It is a key pest of winter maize in the peninsular India (Sekhar et al., 2005) causing dead heart in young and stem tunneling in grown up plants. The losses due to pink stem borer in maize in India vary from 25-80 per cent (Rao et al., 1983). It was reported in the borer complex in Kharif maize in Punjab (Singh et al., 2014). The pest has assumed major pest status in recent time in cereals (Baladhiya et al., 2018). It may pose a serious threat to maize in the rice-wheat/maize based cropping system in Punjab (Singh, 2013). Understanding the detailed biology of the pest on maize is a key to its successful management and sustained maize production in this region. 


\section{Materials and Methods}

The detailed aspects of life cycle of $S$. inferens were studied in 2015 at $25 \pm 1{ }^{\circ} \mathrm{C}$ and $70 \pm 5$ per cent relative humidity under Maize Entomology Laboratory, Punjab Agricultural University (PAU), Ludhiana.

\section{Insect culture}

The larvae were collected from maize fields and were reared in artificial diet as per Kumar and Siddiqui (1993). The adults emerged were made to oviposit on 4-5-day maize seedlings. The seedling pots containing eggs were replaced regularly with fresh pots. The neonates emerged from the eggs $\left(\mathrm{F}_{1}\right.$ population) were reared on artificial diet. The adults emerged were released on maize seedlings to collect the eggs. This $\mathrm{F}_{2}$ population was used for studies on biological parameters. There were 12 replications each having five individuals. The seeds of hybrid PMH 1 were sown in the field as well as in small earthen pots at weekly intervals and maintained to ensure the availability of maize plants throughout the rearing process.

Egg

The number of eggs in each cluster was recorded. The dimensions of the egg $(\mathrm{mm})$ were measured with ocular and stage micrometer.

\section{Larva}

The larvae were reared in 2-2.5 inch long soft stem of 20-25-day-old maize plants individually in Petri dishes and developmental changes were recorded. The body length and breadth were measured using measuring scale. The weight of each instar was recorded using electronic weighing machine (Axis ${ }^{\circledR}$ - AGN 204 PO). The length (vertical) and width (horizontal) of the molted head capsule were taken using ocular micrometer.

\section{Pupa}

The pupae formed were transferred into battery jars lined with moist butter paper having a thin layer of sterile moist sand at the bottom. The jars were covered with cotton cloth. The pupae were sexed and their length, breadth, weight and duration were recorded and kept for adult emergence.

\section{Adult}

The adults emerged were sexed and the length and breadth of the body were taken. Adult pairs were released on seedlings in ovipositional cages. The adults were observed for mating and egg laying. The mean and standard error of different biological parameters were calculated. 


\section{Results}

\section{Egg}

The eggs were semi globular dorsoventrally flattened, with radial ridges (Fig. 1). The eggs have an average length of $0.616 \pm 0.018 \mathrm{~mm}$ and breadth of $0.597 \pm 0.012 \mathrm{~mm}$ (Table 1) (Fig. 2). The freshly laid eggs were creamy white, after 48 hours, head of the embryo became visible. After 72 hours, slight pinkish colour developed with the greyish head visible prominently (Fig. 3). The pinkish colour got relatively darker after 96 hours. After 120 hours of incubation, the eggs changed into greyish black and pink with the black head of the embryo visible clearly. Further, the neonates emerged out of the eggs. The incubation period averaged to $6.82 \pm 0.05$ days. The eggs recorded $92.19 \pm 0.01$ per cent hatchability.

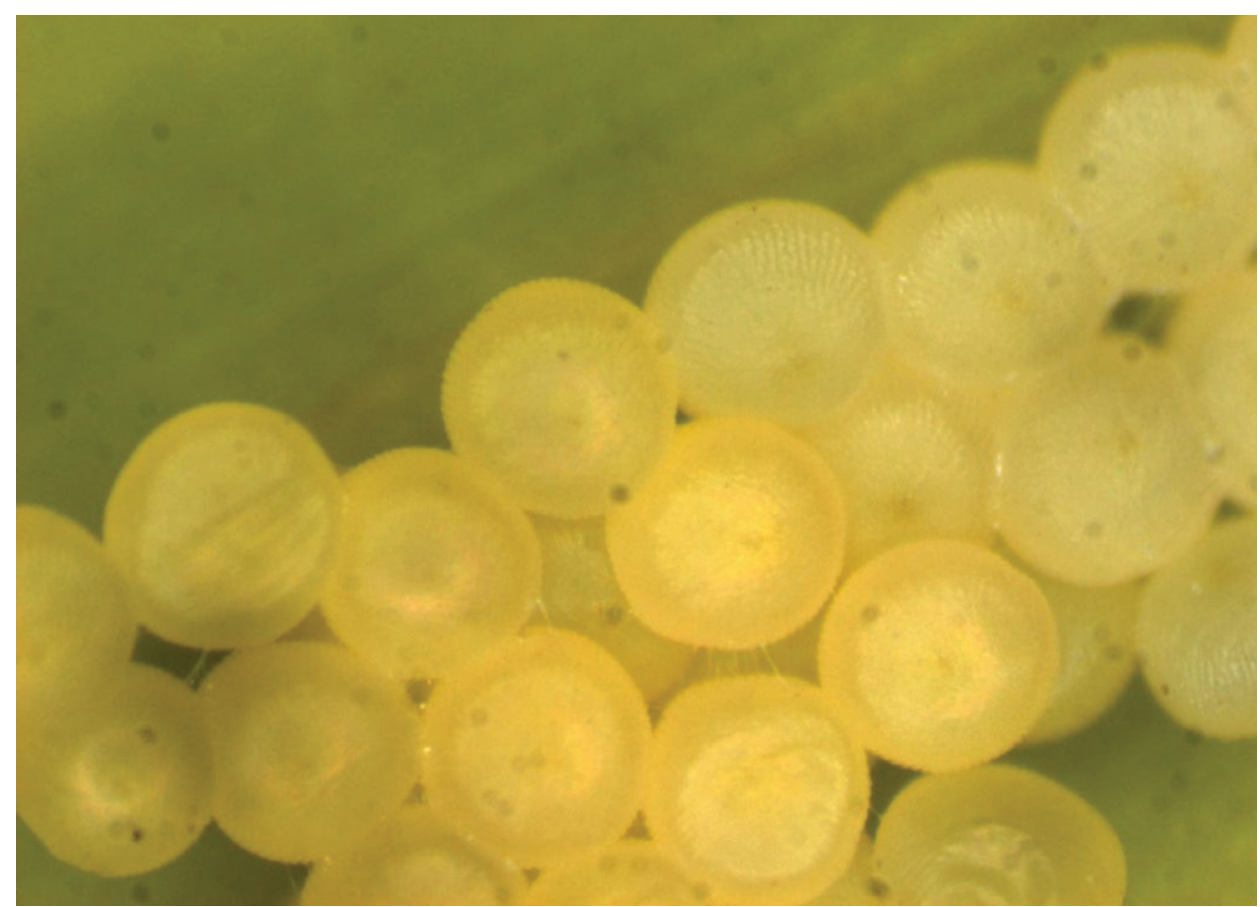

Fig. 1. Egg cluster of Sesamia inferens on maize $(\times 6)$

Table 1

Characters of eggs of $S$. inferens on maize

\begin{tabular}{lcc}
\hline Egg parameters & Range & Mean \pm SE \\
\hline Length (mm) & $0.574-0.660$ & $0.616 \pm 0.018$ \\
Breadth (mm) & $0.502-0.646$ & $0.597 \pm 0.012$ \\
Incubation period (days) & $5-7$ & $6.82 \pm 0.05$ \\
Eggs per cluster (Nos) & $10-102$ & $53.69 \pm 10.78$ \\
Hatchability (\%) & $90-96$ & $92.19 \pm 0.01$ \\
\hline
\end{tabular}




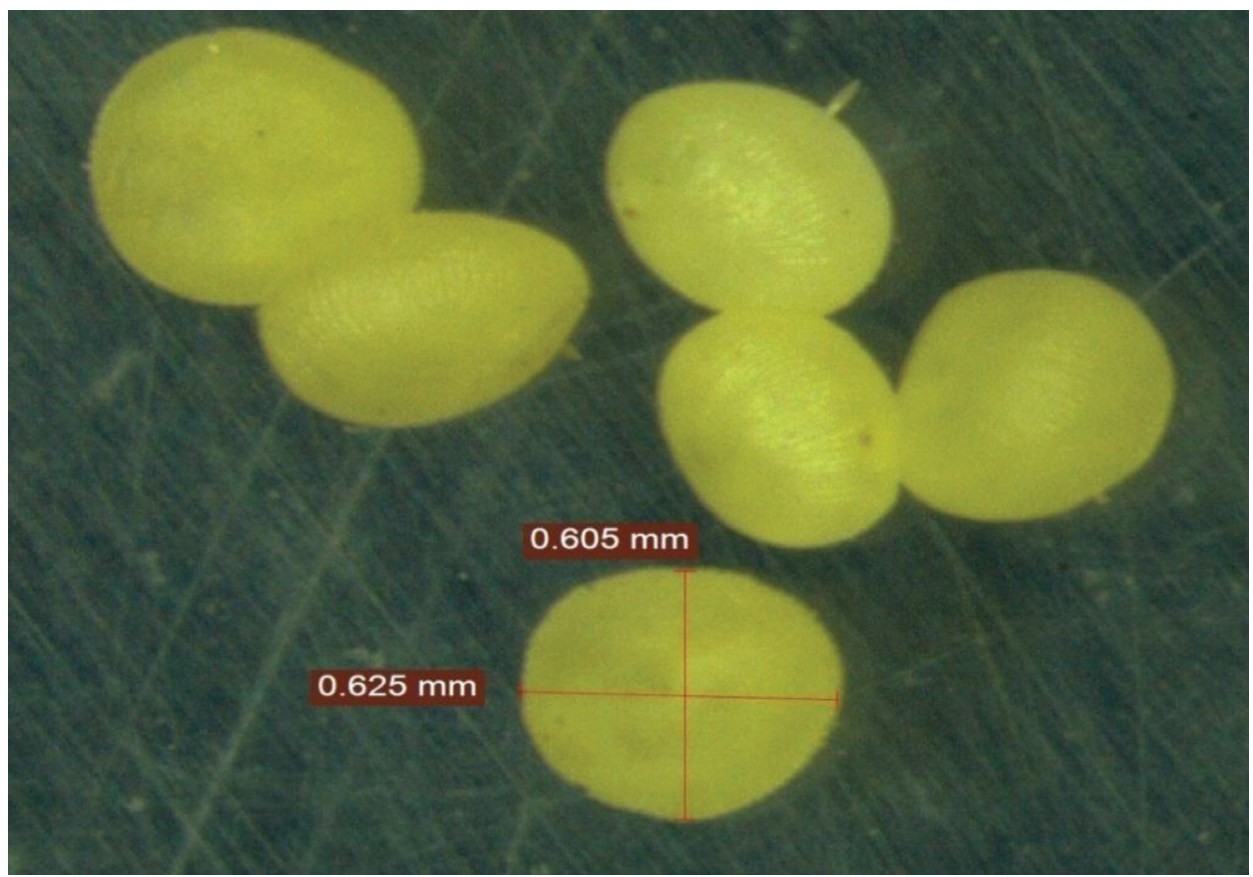

Fig. 2. Dimensions of eggs of Sesamia inferens $(\times 8)$ (A random representative sample)

Eggs were laid in batches, in 2-4 long rows. The adult females laid eggs in the inner side of the first three leaf sheaths, preferably in the first leaf sheath. Number of eggs per cluster varied from 10 to 102, with an average of 53.69 \pm 10.78 eggs (Table 1 ).

\section{Larva}

The larva passed through six larval instars. The newly hatched larva was cream in colour with black head. The pink colour started developing on the larval body at the second instar and by fourth instar the colour became prominent. The molting pattern of the larvae is described (Fig. 4). The head capsule of the newly molted larvae was light yellowish cream, which gradually changed to light brown, dark brown and finally greyish black.

The duration of the larval instars I-VI was $4.17 \pm 0.09,3.60 \pm 0.08,4.47 \pm 0.02$, $4.40 \pm 0.03,6.18 \pm 0.06$ and $7.13 \pm 0.05$ days, respectively (Table 2). The total larval development was completed in $29.95 \pm 0.16$ days. The length of larval instars I-VI averaged to $2.10 \pm 0.06,4.34 \pm 0.25,8.83 \pm 0.31,14.50 \pm 0.42,20.83 \pm 0.55$ and $27.17 \pm 0.49 \mathrm{~mm}$, respectively. The breadth of larval instars I-VI were $0.49 \pm 0.02,0.67 \pm 0.03,2.00 \pm 0.13$, $2.35 \pm 0.10,2.92 \pm 0.90$ and $3.48 \pm 0.05 \mathrm{~mm}$, respectively. The different larval instars had an average weight of $0.18 \pm 0.02,4.20 \pm 0.68,34.48 \pm 5.01,70.99 \pm 2.89,123.68 \pm 5.80$ and $223.58 \pm 6.61 \mathrm{mg}$, respectively. The molted head capsule of the instars I-VI measured $0.429 \pm 0.005,0.488 \pm 0.008,0.849 \pm 0.010,0.997 \pm 0.013,1.518 \pm 0.014$ and $1.944 \pm 0.008 \mathrm{~mm}$ length (vertical). The width (horizontal) of the molted head capsule of six larval instars was $0.38 \pm 0.006,0.46 \pm 0.004,0.78 \pm 0.015,0.88 \pm 0.005,1.31 \pm 0.031$ and $1.79 \pm 0.015 \mathrm{~mm}$, respectively (Fig. 5). The larvae stopped feeding and a few white 


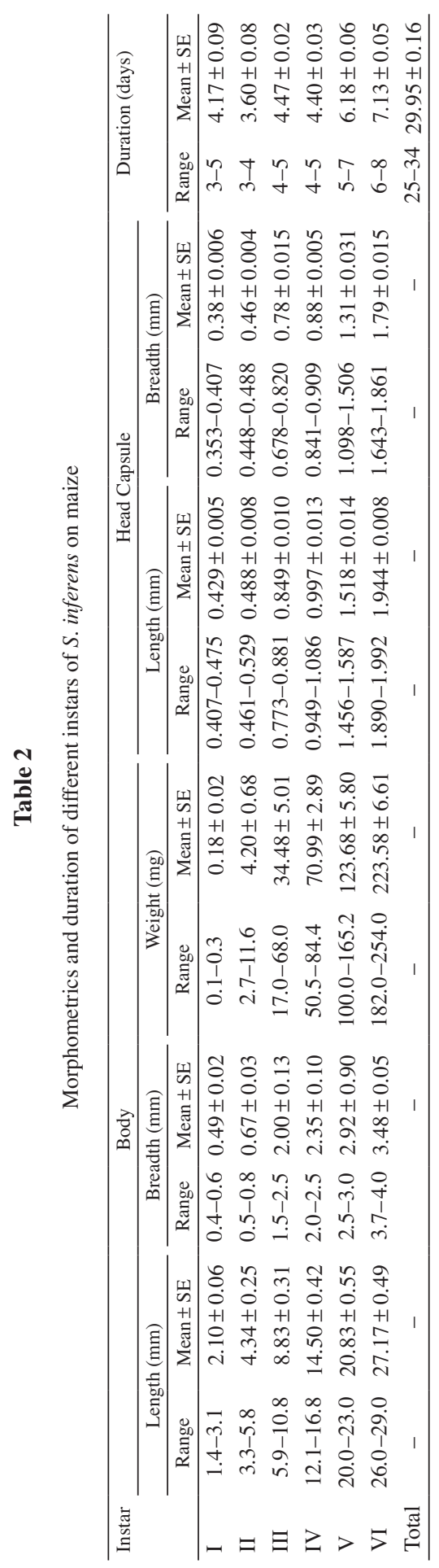



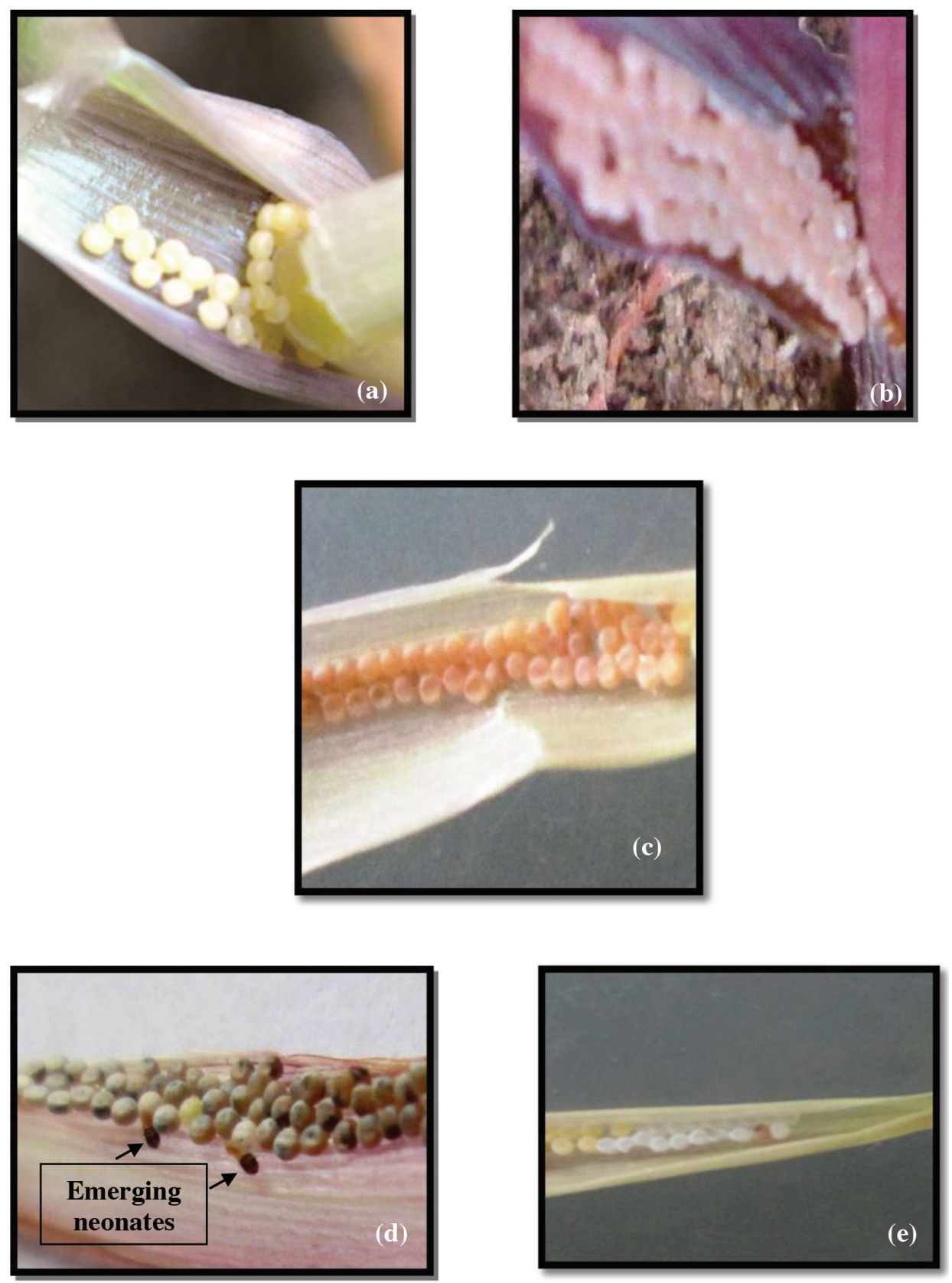

Fig. 3. Sequence of changes in the eggs of Sesamia inferens (a) Freshly laid eggs in cluster;

(b) Eggs changed to pink colour; (c) Dark pink coloured eggs;

(d) Greyish black and pink eggs with head of embryo visible properly and neonates started emerging;

(e) Empty egg shell left after the emergence of neonates 

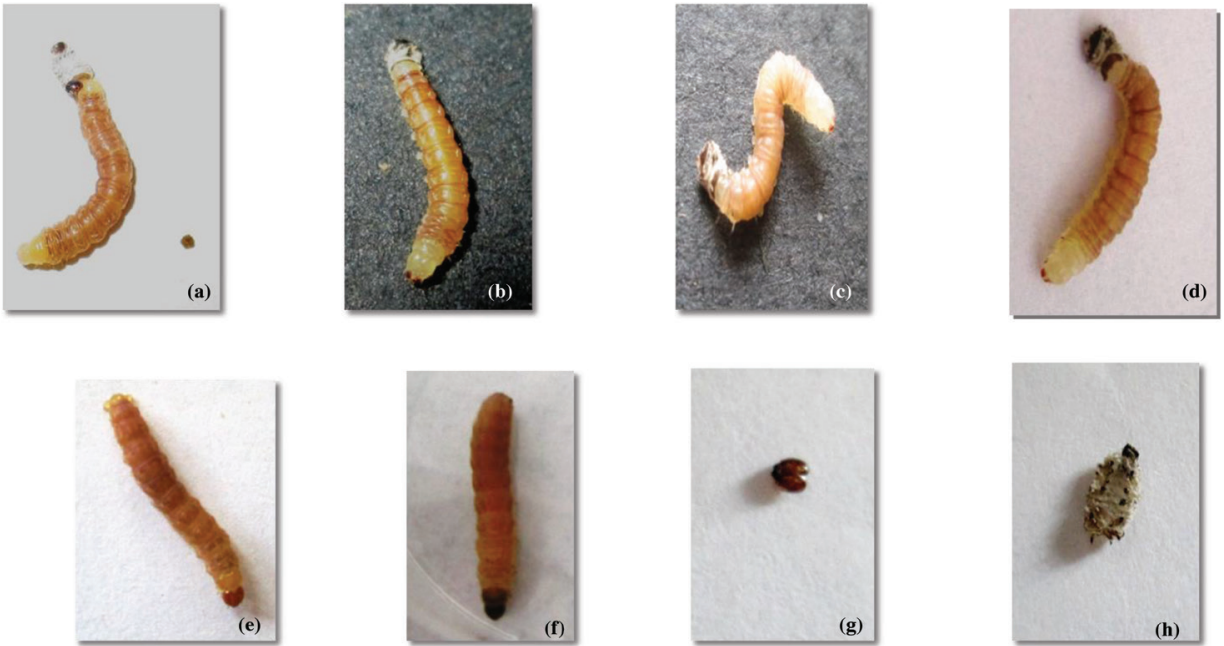

Fig. 4. Molting pattern of larvae of Sesamia inferens (a)-(d) Larval molting;

(e) Molted larva with brown head capsule; (f) Brown head capsule turned to black;

(g) Molted head capsule; (h) Exuvia of Sesamia inferens
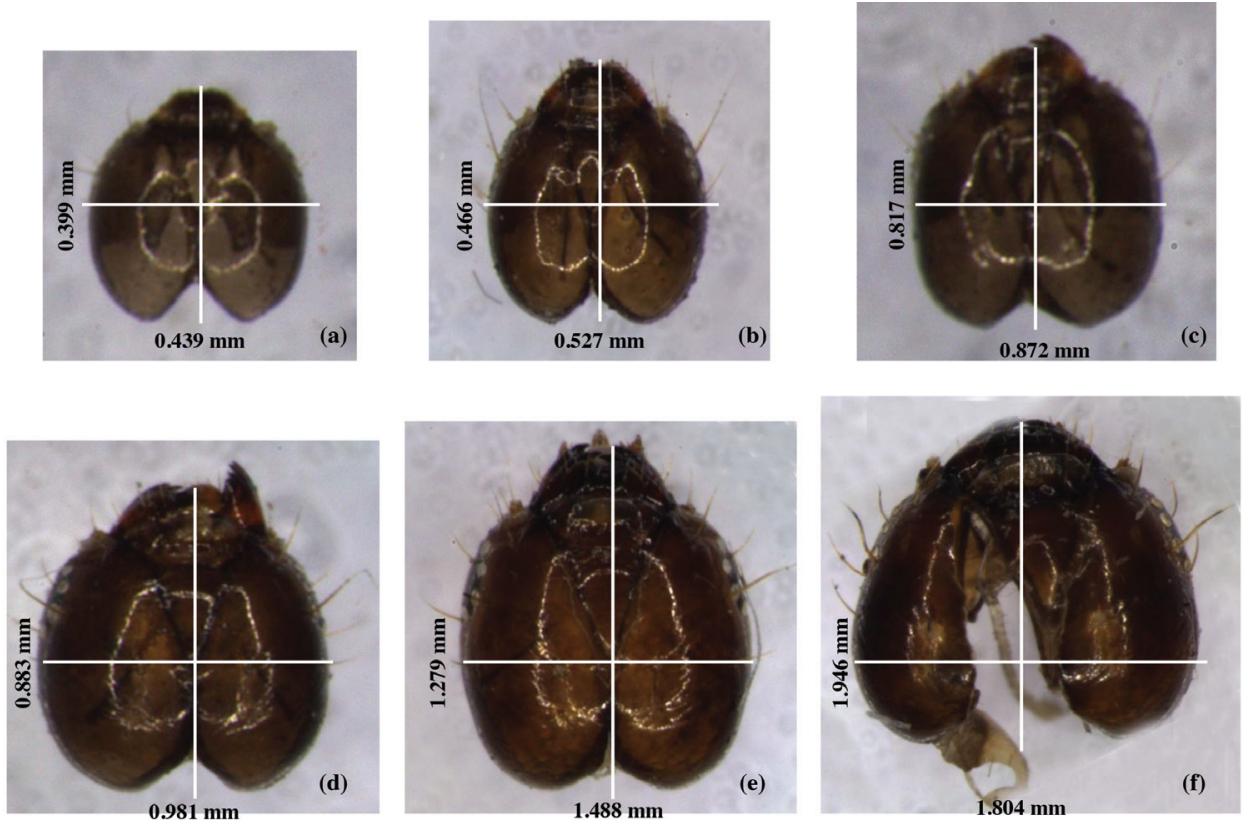

Fig. 5. Dimensions of larval head capsule of Sesamia inferens (a)-(f) Molted head capsules of 1-6 larval instars (Random representative samples) 
Table 3

Pre-pupal and pupal characters and total life cycle of S. inferens on maize

\begin{tabular}{lcc}
\hline Parameters & Range & Mean \pm SE \\
\hline $\begin{array}{l}\text { Pre-pupal duration (days) } \\
\text { Pupal duration (days) }\end{array}$ & $2-3$ & $2.83 \pm 0.02$ \\
$\quad$ Male & $7-10$ & $8.05 \pm 0.12$ \\
$\quad$ Female & $8-12$ & $10.33 \pm 0.16$ \\
Pupal length (mm) & & \\
$\quad$ Male & $11.07-13.50$ & $12.17 \pm 0.22$ \\
$\quad$ Female & $13.80-16.10$ & $14.59 \pm 0.28$ \\
Pupal breadth (mm) & & \\
$\quad$ Male & $2.82-4.10$ & $3.15 \pm 0.10$ \\
$\quad$ Female & $3.50-5.00$ & $4.01 \pm 0.20$ \\
Pupal weight (mg) & & $130.60 \pm 4.30$ \\
$\quad$ Male & $102.10-173.50$ & $194.30 \pm 8.30$ \\
$\quad$ Female & $153.70-260.60$ & \\
Total life cycle (days) & & $47.65 \pm 0.24$ \\
$\quad$ Male & $39-54$ & $49.93 \pm 0.21$ \\
$\quad$ Female & $40-56$ & \\
\hline
\end{tabular}

silken threads were produced around the body. The body gradually got shrunk length wise inside the silken web, finally becoming slightly curved (Fig. 6). The pre-pupal period lasted for $2.83 \pm 0.02$ days (Table 3 ).

Pupa

The pre-pupa gradually changed to obtect pupa. The male pupa had a length of $12.17 \pm 0.22 \mathrm{~mm}$ and a breadth of $3.15 \pm 0.10 \mathrm{~mm}$ (Table 3) (Fig. 7). The length of female pupa was $14.59 \pm 0.28 \mathrm{~mm}$ and the breadth was $4.01 \pm 0.20 \mathrm{~mm}$. The male pupa weighed $130.60 \pm 4.30 \mathrm{mg}$ while, the female weighed $194.30 \pm 8.30 \mathrm{mg}$. The structures like, the eye, antenna, forewings and the abdomen region of the future adult were clearly visible in the pupa (Fig. 8). The pupal period of male and female were $8.05 \pm 0.12$ days and $10.33 \pm 0.16$ days, respectively. The life cycle of $S$. inferens (Fig. 10) was completed in $47.65 \pm 0.24$ (39-54) days in males and $49.93 \pm 0.21(40-56)$ days in females (Table 3$)$.

\section{Adult}

The colour of $S$. inferens varied from light straw to medium brown (Fig. 9). Males had smaller body size than females. The males had a body length of $12.50 \pm 0.41 \mathrm{~mm}$ and width of $3.40 \pm 0.11 \mathrm{~mm}$ (Table 4), weighing $107.78 \pm 3.47 \mathrm{mg}$. They had a wing expanse of $21.41 \pm 0.19 \mathrm{~mm}$ with a single wing length of $12.45 \pm 0.23 \mathrm{~mm}$. The body length and width of female was $15.55 \pm 0.18$ and $4.60 \pm 0.13 \mathrm{~mm}$, respectively with a weight of $188.52 \pm 10.53 \mathrm{mg}$. The females had a larger wing expanse of $31.00 \pm 0.36$ $\mathrm{mm}$ and a single wing length of $14.57 \pm 0.19 \mathrm{~mm}$. The longevity of male was $3.92 \pm 0.23$ days and that of female was $5.05 \pm 0.28$ days (Table 4 ). The pre-oviposition period of fe- 
Table 4

Morphometrics and longevity of adults of $S$. inferens on maize

\begin{tabular}{lccccc}
\hline Adult parameters & \multicolumn{2}{c}{ Male } & & \multicolumn{2}{c}{ Female } \\
\cline { 2 - 3 } \cline { 5 - 6 } & Range & Mean \pm SE & & Range & Mean \pm SE \\
\hline Length $(\mathrm{mm})$ & $10.0-14.5$ & $12.50 \pm 0.41$ & & $14.5-16.5$ & \\
Breadth $(\mathrm{mm})$ & $3-4$ & $3.40 \pm 0.11$ & & $4.0-5.5$ & $15.55 \pm 0.18$ \\
Weight $(\mathrm{mg})$ & $70.30-156.46$ & $107.78 \pm 3.47$ & & $102.00-363.70$ & $188.52 \pm 10.53$ \\
Wing expanse (mm) & $20-22$ & $21.41 \pm 0.19$ & & $29-33$ & $31.00 \pm 0.36$ \\
Single wing length (mm) & $11.0-13.4$ & $12.45 \pm 0.23$ & & $13.4-15.5$ & $14.57 \pm 0.19$ \\
Longevity (Days) & $3-5$ & $3.92 \pm 0.23$ & & $4-6$ & $5.05 \pm 0.28$ \\
\hline
\end{tabular}

Table 5

Biological parameters of $S$. inferens on maize

\begin{tabular}{lcc}
\hline Parameter & \multicolumn{2}{c}{ Period (Days) } \\
\cline { 2 - 3 } & Range & Mean \pm SE \\
\hline Pre-oviposition period & $1.1-1.7$ & $1.11 \pm 0.10$ \\
Oviposition period & $2.0-4.0$ & $2.96 \pm 0.19$ \\
Post-oviposition period & $0.5-1.2$ & $0.79 \pm 0.10$ \\
Adult emergence (\%) & $91.67-95.65$ & $93.02 \pm 0.01$ \\
Sex ratio (Male: Female) & $1: 1-1: 1.8$ & $1: 1.05$ \\
Fecundity (Nos. per female) & $152-286$ & $211.92 \pm 11.92$ \\
\hline
\end{tabular}

males was $1.11 \pm 0.10$ days (Table 5). The oviposition period was $2.96 \pm 0.19$ days and the post-oviposition period was $0.79 \pm 0.10$ days. Peak period of mating occurred in the night at 21.00-24.00 hours and lasted for about 1 hour. The females laid eggs on the inner side of basal leaf sheaths in 3 to 4 non-overlapping rows.

An adult emergence of 91.67-95.65 per cent was recorded with an average of $93.02 \pm 0.01$ per cent (Table 5). The male to female sex ratio was found to vary from 1:1 to $1: 1.18$ with an average of $1: 1.05$. The fecundity varied from 152-286 eggs with an average of $211.92 \pm 11.92$ eggs. The maximum number of eggs was laid on the second day of emergence.

\section{Discussion}

The variability in biology of $S$. inferens was reported on different host plants under variable agroclimatic conditions. The morphometric features of the eggs of S. inferens reported by Aggarwal et al. (2004), Rajendra (1976) and Singh (2013) on different crops were in line with the present study. However, variation in the incubation period is documented. Sekhar et al. (2005) reported a comparable incubation period of 5-8 days on maize. The longer period of 6-11 days during October-November (Aggarwal et al., 2004) and $7.40 \pm 0.38$ days during November-January (Singh, 2013) may be attributed to the low temperature. The slower embryonic development at lower temperature (Viswajyothi et al., 2017) might have resulted in delayed development. However, egg hatchability corroborates with reports of Selvaraj et al. (2014) and Singh (2013). The 


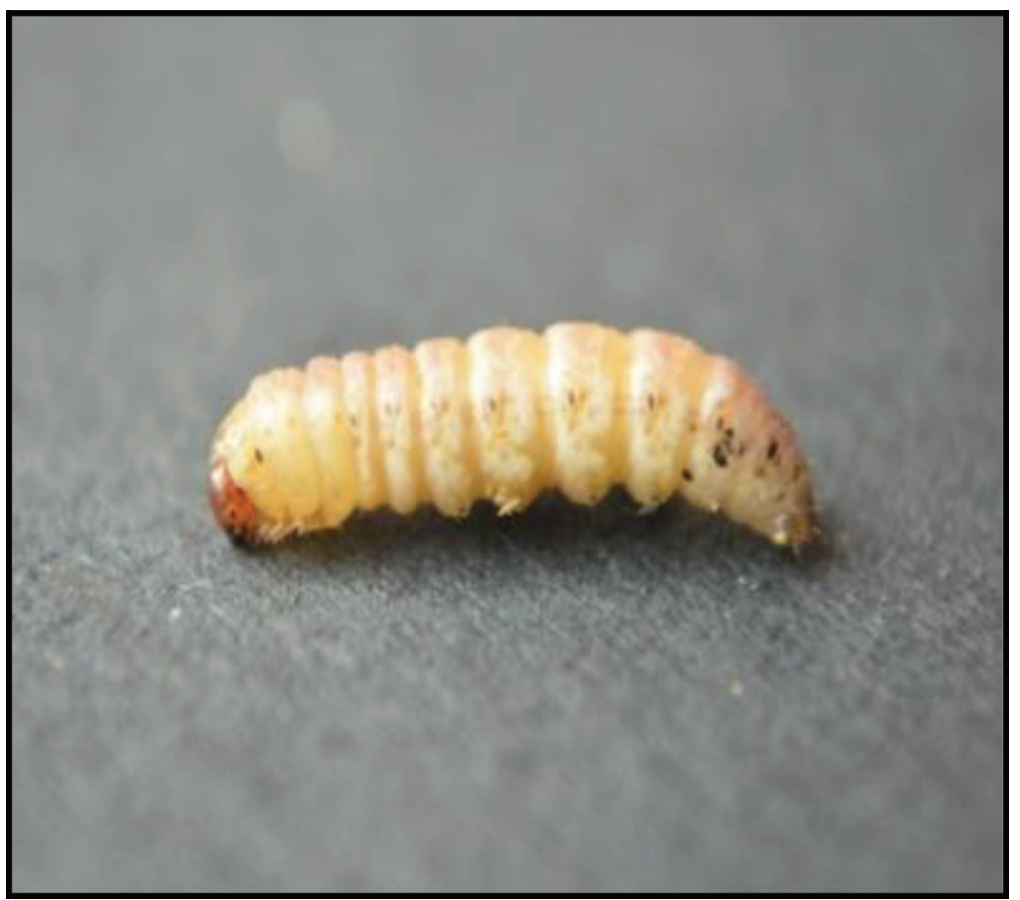

Fig. 6. Pre-pupa of Sesamia inferens

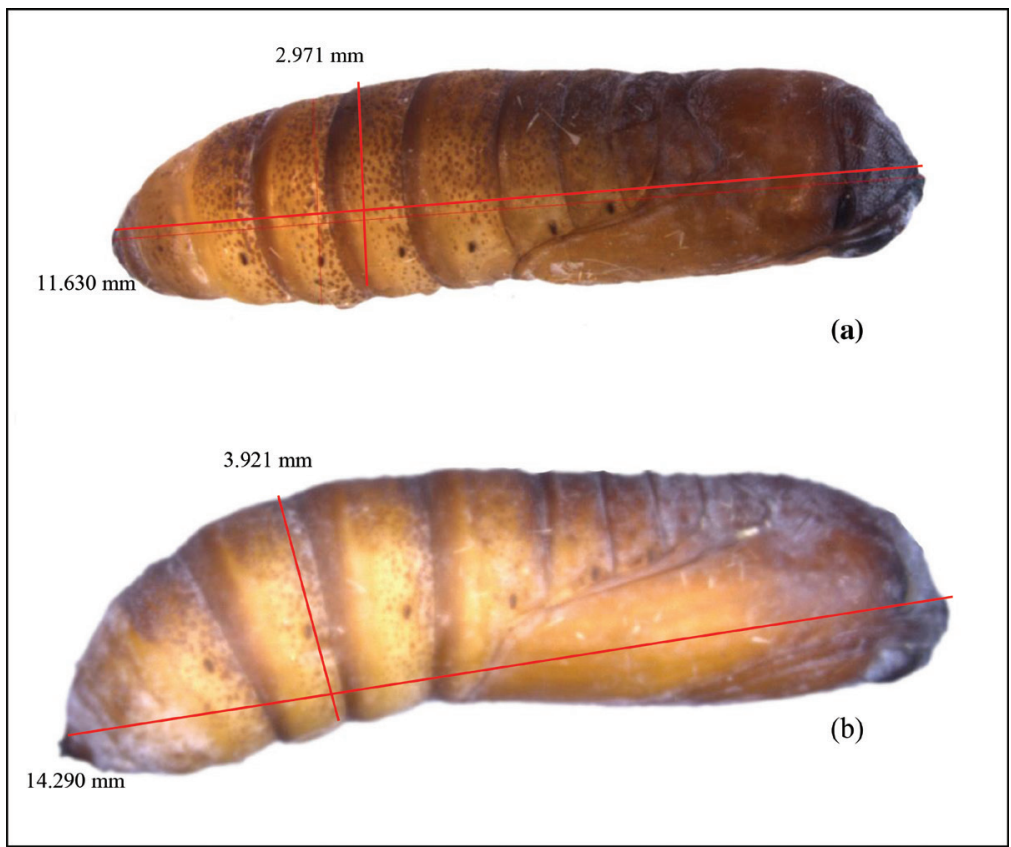

Fig. 7. Pupa of Sesamia inferens (a) Male pupa $(\times 10)$; (b) Female pupa $(\times 8)$ (A random representative sample) 


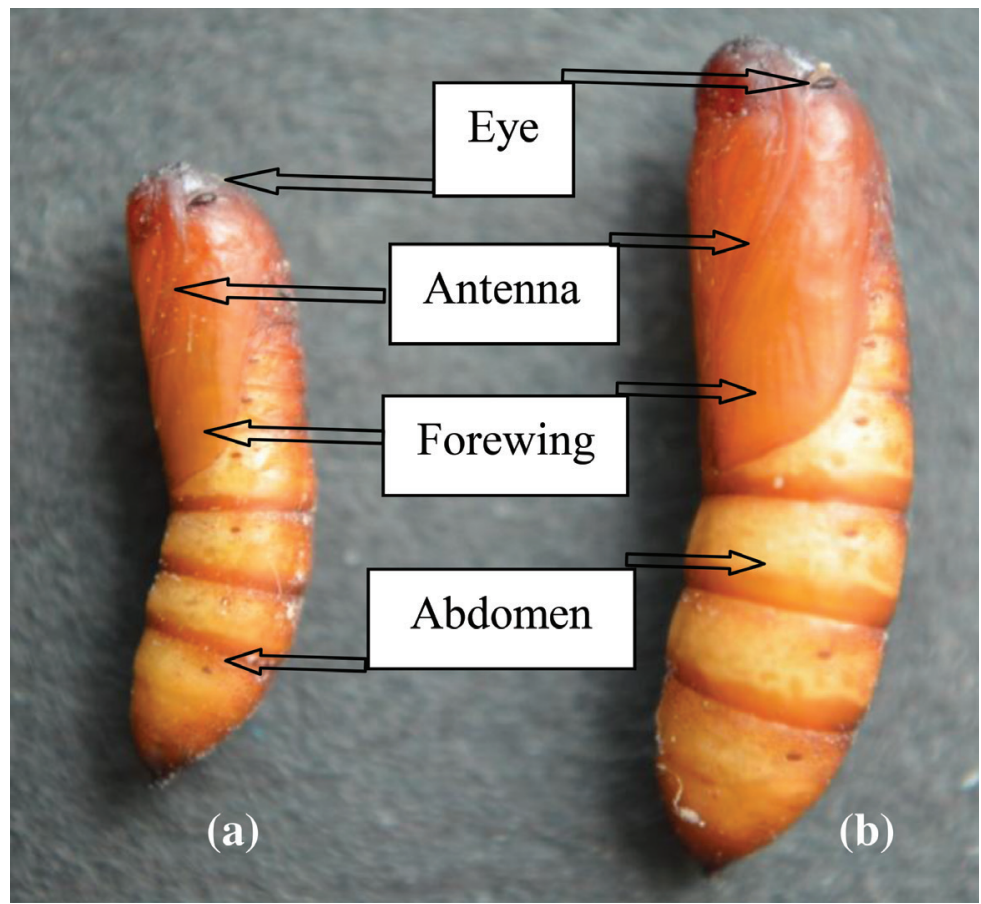

Fig. 8. Body regions of pupa (a) Male; (b) Female

number of eggs per cluster showed variability. Similar to present studies, Aggarwal et al. (2004) reported 15 to 91 eggs per cluster with a mean of 58.84 \pm 3.60 eggs on rice but on contrary Rajendra (1976) reported 50-150 eggs per cluster in sugarcane crop from Sri Lanka. This variation may be due to the crop, varieties and the environmental conditions on which the insect was reared. The pattern of oviposition in first leaf sheaths was similar to that reported by Kaur et al. (2015) on maize. However, Singh (2013) on wheat recorded the oviposition either at the base of the plant or on soil surface or in the stubbles of rice crop. The variation describes the ability of the insect species to select the ideal oviposition substrate.

The present studies revealed the occurrence of 6 larval instars of the pest in maize. However, 8 instars have been reported by Rajendra (1976) in sugarcane and Singh (2013) in wheat and 6-8 in rice by Aggarwal et al. (2004). The number of instars of the pest varies with host plants and it increases under stress conditions (Singh 2013). The duration of different larval instars observed is similar to that reported by Aggarwal et al. (2004) on rice. Singh (2013) reported slightly longer duration and attributed this to the difference in host, season and larval instars as wheat is grown in the winter season. The length and breadth of different larval instars observed in the present study is in line with that of Aggarwal et al. (2004) in rice crop, but was more as compared to findings of Rajendra (1976) in sugarcane. In contrast to the findings, longer duration has been reported by Aggarwal et al. (2004), Rajendra (1976) and Singh (2013).

The duration of pre-pupal period is consistently reported by various workers. However, variation is observed in pupal duration. Aggarwal et al. (2004) in rice and Singh 

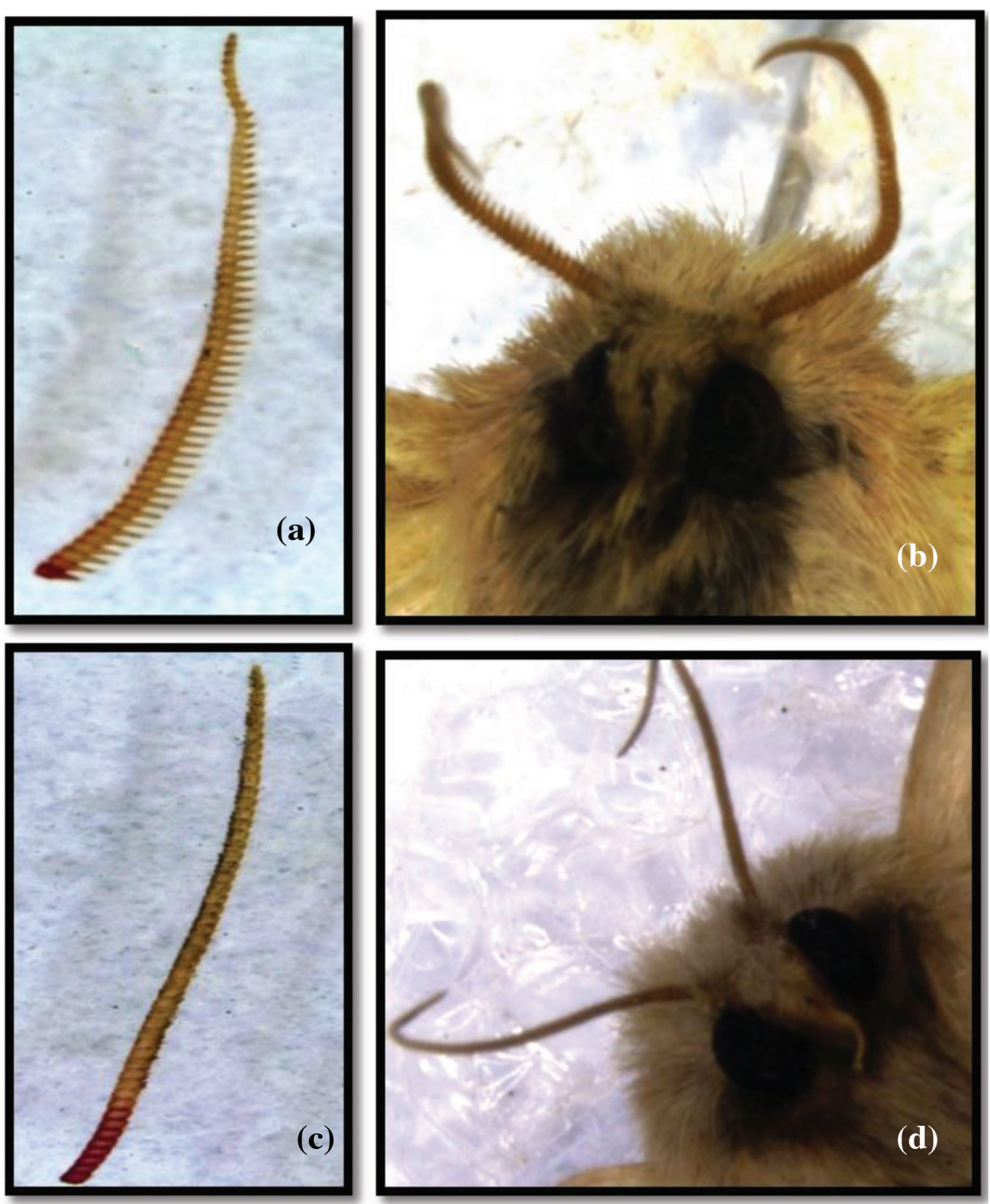

Fig. 9. Antenna of adults of Sesamia inferens $(\mathrm{a})(\times 15)$ and $(\mathrm{b})(\times 10.7)$ Pectinate antenna of male; $(c)(\times 15)$ and $(d)(\times 10.7)$ Filiform antenna of female

(2013) in wheat has reported longer duration than present studies. The length and breadth of pupa reported in the present study are in agreement with that of Aggarwal et al. (2004). The weight of male and female pupa observed in the present study was comparatively less than that reported by Singh (2013). That might be due to the accumulation of more reserves in the hibernating winter population of S. inferens.

Adult morphometry features of $S$. inferens recorded presently and by earlier workers revealed minor variations. However, Singh (2013) reported higher average weight 


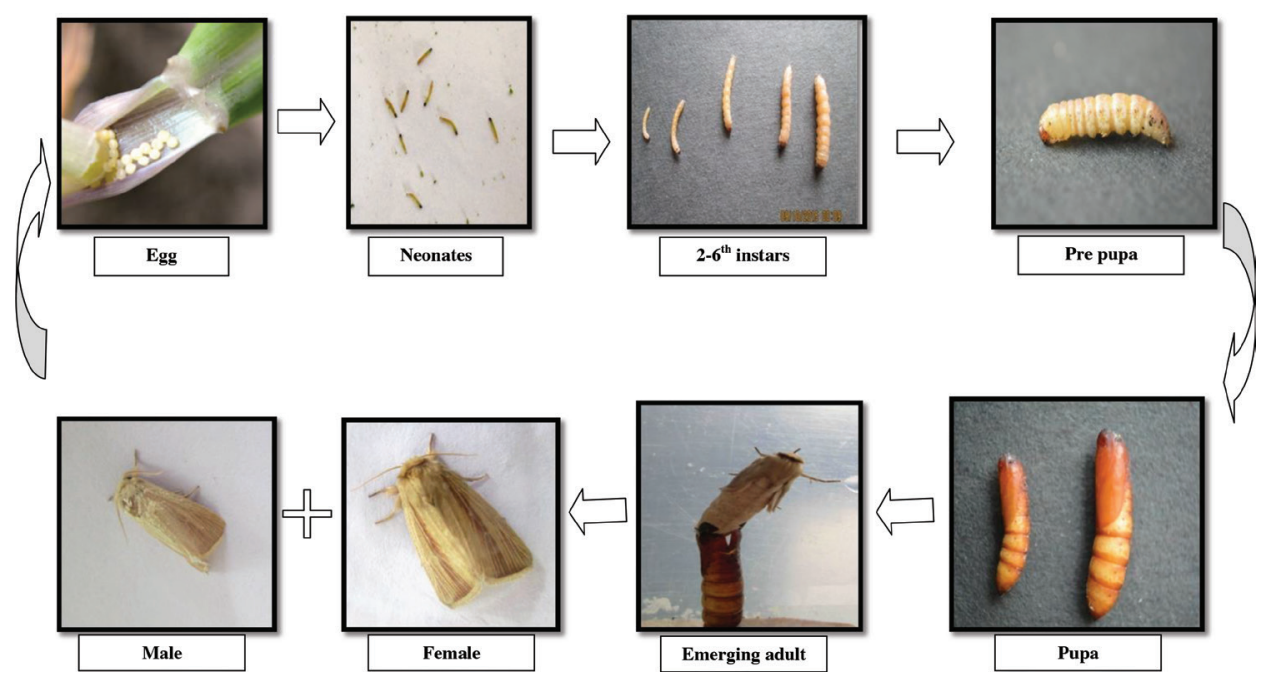

Fig. 10. Life cycle of Sesamia inferens on maize

of $184.95 \pm 10.17 \mathrm{mg}$ for male and $241.55 \pm 21.65 \mathrm{mg}$ for female adults on wheat crop during winter season which might be due to higher larval weight of the hibernating population. The observations on adult longevity by earlier workers are in agreement with the present study. Reigada et al. (2016) also reported no difference in adult longevity in Helicoverpa armigera on different nutritionally suitable hosts. But, if the host plants are nutritionally different, the adult longevity differs significantly (Liu et al., 2004). The pre-oviposition ( $1.42 \pm 0.05$ days), oviposition ( $1.89 \pm 0.12$ days $)$ and post oviposition period of $2.42 \pm 0.10$ days in rice reported by Aggarwal et al. (2004) was in tune with the present study. However, longer pre-oviposition (1.65 \pm 0.21 days) and oviposition period (4.82 \pm 0.54 days) was reported by Singh (2013) in wheat. The observation on adult emergence $(95.8 \%)$ and male to female sex ratio (1:1.04) is similar to Selvaraj et al. (2014) and Aggarwal et al. (2004) in rice, respectively.

The average fecundity in earlier findings on different hosts is in line with the present study except that of Singh (2013) on wheat in winter, who reported lower fecundity of $118.33 \pm 12.04$ eggs. Similarly, Khadioli et al. (2014) reported that the fecundity of Sesamia calamistis reared on artificial diet, reduced with decrease in temperature.

The duration and morphometrics of $S$. inferens in the present study is in general agreement with that of Sharma et al. (2017) on maize crop studied during October to December. However, their December to march study deviates much from the present study. The total life cycle of $S$. inferens in the present study is in harmony with Aggarwal et al. (2004) on rice crop. However, Sehkar et al. (2005) recorded 40-83 days on maize due to prolongation of larval period during unfavorable conditions and Singh (2013) reported 116.92 to 119.95 days in wheat during winter season. The present study deviates from these earlier reports primarily due to the influence of prevalent temperature on the duration of developmental stages (Viswajyothi et al., 2017). The larva also undergo diapauses at lower temperature which further increase the duration of total life cycle. Population enters diapauses at lower temperature where larva continue to grow and moult without pupation (Eizaguirre et al., 2002). Singh (2013) observed that the larval period got extended on wheat. Fantinou et al. 
(1995) demonstrated diapause induction in Sesamia nonagrioides, resulting in longer generation time with decrease in temperature when reared on artificial diet.

The present finding will serve as a bench mark for studying bionomics, assessing damage potential and management of $S$. inferens on maize under Punjab conditions. However, the variation in the life cycle with respect to weather parameters, especially temperature should be taken into consideration.

\section{Acknowledgements}

We thank the Department of Entomology and Department of Plant Breeding and Genetics, Pandjab Agricultural university Ludhiana for providing the facilities for conducting the research successfully.

\section{Conclusion}

Sesamia inferens feeds on the economically important graminaceous crops including rice, wheat, maize and sugarcane. It is increasingly coming up in maize crop in the north western plains of India. Maize is being widely preferred by the farmers in the north western plains of the country, because of the wider adaptability and higher productivity of the crop. Thus, the increasing incidence of the pest in the region is of major concern. The biology of $S$. inferens was studied at $25 \pm 1^{\circ} \mathrm{C}$ and $70 \pm 5$ per cent relative humidity on PMH 1 maize hybrid. It took 47.65 days (male) and 49.93 days (female) to complete the development, passing through 6 larval instars, completing larval development in $29.95 \pm 0.16$ days. The adults had a sex ratio of 1:1.05 and fecundity of $211.92 \pm 11.92$ eggs. The observations are in general agreement with that of earlier workers who have conducted the experiments under comparable temperature conditions to the present study. Though variation is also observed with different host, temperature seems to be the major factor influencing the biology. The study on the detailed biology of the pest is necessary to develop successful integrated pest management strategies and to ensure sustained maize production in the region.

\section{Literature}

Aggarwal, R., Singh, J. and Shukla, K. K. (2004): Biology of pink stem borer, Sesamia inferens Walker on rice crop. Indian J. Ecol. 31, 66-67.

Baladhiya, H. C., Sisodiya, D. B. and Pathan, N. P. (2018): A review on pink stem borer, Sesamia inferens Walker: A threat to cereals. J. Entomol. Zool. Stud. 6(3): 1235-1239.

Eizaguirre, M., López, C. and Sans, A. (2002): Maize phenology influences field diapause induction of Sesamia nonagrioides (Lepidoptera: Noctuidae) Bull. Entomol. Res. 92, 439-443. doi:10.1079/BER2002183.

Fantinou, A. A., Karandinos, M. G. and Tsitsipis, A. A. (1995): Diapause induction in the Sesamia nonargioides (Lepidoptera: Noctuidae). Effect of photoperiod and temperature. Environ. Entomol. 24, 1458-1466.

Hampaon, G. F., Bart., F. Z. S., F. E. S. (1912): The moths of India, supplementary paper to the volumes in "The Fauna of British India.” Series IV, Part III. J. Bombay Nat. Hist. Soc. 21(3), 878-911.

Kaur, J., Kumar, P., Singh, J., Suby, S. B. and Bajya, D. R. (2015): Egg laying pattern of Sesamia inferens on maize (Zea mays). Indian J. Agric. Sci. 85, 109-113. 
Khadioli, N., Tonnang, Z. E. H., Ong'amo, G., Achia, T., Kipchirchir, I., Kroschel, J. and Ru, B. Le. (2014): Effect of temperature on the life history parameters of noctuid lepidopteran stem borers, Busseola fusca and Sesamia calamistis. Ann. Appl. Biol. 165, 373-386. doi:10.1111/aab.12157.

Kumar, S. P. and Siddiqui, K. H. (1993): Compounding artificial diets for rearing the pink stem borer, Sesamia inferens Walker. J. Ent. Res. 17, 81-90.

Liu, Z., Li, D., Gong, P. and Wu, K. (2004): Life table studies of the cotton bollworm, Helicoverpa armigera (Hübner) (Lepidoptera: Noctuidae), on different host plants. Environ. Entomol. 33, 1570-1576.

Rajendra, A. (1976): Studies on Sesamia Inferens Wlk. The shoot-borer pest of sugarcane in Sri Lanka. J. Nat. Sci. Coun. Sri Lanka 4, 99-108.

Rao, S., Venugopal, C. N. and Razvi, S. A. (1983): Parasitism, a key factor in checking rice pest population. Entomon. 8, 97-100.

Reigada, C., Guimaraes, K. F. and Parra, J. R. P. (2016): Relative fitness of Helicoverpa armigera (Lepidoptera: Noctuidae) on seven host plants: A perspective for IPM in Brazil J. Insect Sci. 16, 1-5. doi:10.1093/ jisesa/iev158

Sekhar, J. C., Sharma, V. K., Reddy, R. K., Chaudhary, M. L. K. and Singh, N. N. (2005): Pink stem borers (Sesamia spp.) - Major threat for tropical maize. In: P. H. Zaidi and N. N. Singh (eds): Stresses on Maize in Tropics. DMR, New Delhi, pp. 396-435.

Selvaraj, K., Chander, S. and Prasannakumar, N. R. (2014): Determination of thermal constant and development threshold of pink borer, Sesamia inferens Walker. Proc. Nat. Acad. Sci., India, Sect B. Biol. Sci. 85, $659-662$.

Sharma, H., Jaglan, M. S. and Yadav, S. S. (2017): Biology of pink stem borer, Sesamia inferens (Walker) on maize, Zea mays. J. Appl. Nat. Sci. 9, 1994-2003.

Singh, B. (2013): Bionomics of pink stem borer, Sesamia inferens Walker (Lepidoptera: Noctuidae) in paddy-wheat cropping system. Ph.D. dissertation, PAU, Ludhiana.

Singh, G., Jindal, J. and Kumar, M. (2014): Incidence and extent of losses by cob borer complex on Kharif maize in Punjab. Proc. Int. Conf.: Changing Scenario of Pest Problems in Agri-horti Ecosystem and their Management. MPUAT, Udaipur, $171 \mathrm{p}$.

Viswajyothi, K., Aggarwal, N. and Jindal, J. (2017): Thermal indices of pink stem borer, Sesamia inferens Walker on maize in North-Western plains of India. Indian J. Ecol. 44, 893-897. 
